\title{
Fecundity, natality, and weight as a function of prenatal alcohol consumption and age of the mother
}

\author{
DAVID S. PHILLIPS and GENE L. STAINBROOK \\ Department of Medical Psychology, University of Oregon Health Sciences Center \\ Portland, Oregon 97201
}

\begin{abstract}
The purpose of this study was to investigate the possible interaction between prenatal exposure to alcohol and the age of the mother upon offspring. Two groups of female rats, one who drank only water and one who drank only wine, were mated four times. The fecundity, natality, and weights of the pups were examined. It was concluded that in the rat moderate amounts of alcohol do not affect fecundity but that natality is affected. Birth weight of the pups is also affected by maternal alcohol consumption but not by the age of the mother.
\end{abstract}

Numerous investigators have reported cases involving human infants with birth defects born to alcoholic mothers (Bianchine \& Taylor, 1974; Ferrier, Nicol, \& Ferrier, 1973; Hall \& Orenstein, 1974; Jones \& Smith, 1973; Jones, Smith, Streissguth, \& Myrianthopoulos, 1974). Typically, these infants are small in terms of height, weight, and head circumference, have small palpebral fissures, microphthalamia, epicanthal folds, and cardiac anomalies (Jones, Smith, Ullelund, \& Streissguth, 1973). Those who have been followed postnatally have shown retarded development physically and behaviorally. The phrase "fetal alcohol syndrome," or FAS, has been used as a label for this condition.

While the number of reported cases of FAS is relatively small compared to the total number of alcoholic women, the number of reported cases has been increasing markedly since FAS was first brought to the attention of the medical community. More recently, prospective studies have been conducted showing that some aspects of FAS may occur in offspring born to women who are social drinkers as well as to offspring of alcoholics (Hanson \& Smith, Note 1; Streissguth \& Barr, Note 2). There does appear to be a dose-response relationship in that the degree and perhaps the frequency of impairment appears to be less in children of social drinkers.

In comparing the various prospective and retrospective studies, one notes a variety of differences between the populations studied. The typical prospective study experimental subject is a young, primigravid social drinker, while the typical experimental subject in the retrospective studies is an older, multi-

This research was supported in part by NIAAA 5 T32 AA07074-03. gravid alcoholic. While direct comparison between the two types of study is difficult, there is some suggestive evidence that the frequency and severity of impairment is greater in the retrospective studies. Usually this is attributed to the larger volumes of alcohol consumed by the subjects, but it is well known that older, multigravid females are more prone to produce offspring with congenital defects, so that while the increased effect may be dose dependent it may also be due to the increased age of the mother or to a combination of alcohol and age.

The present study was designed to investigate the possible interaction between alcohol consumption and age of the mother on the outcome of pregnancy. Fecundity (the ability to produce offspring), natality (birth rates), and weight of offspring were examined in rats. Rats were selected as experimental subjects since they breed rapidly and have been shown to be sensitive to developmental perturbations when administered substances prenatally (Butcher, Vorhees, \& Kimmel, 1972; Golter \& Michaelson, 1975; Havlena \& Werboff, 1963; Phillips \& Stainbrook, 1976).

\section{METHODS}

Six female hooded rats were randomly selected at weaning from stock born in our colony, randomly assigned to one of two groups and individually housed in $15 \times 30 \times 36 \mathrm{~cm}$ Plexiglas cages with wire tops. Throughout the experiment, the animals had ad-lib access to food and fluid. At 60 days of age, the animals in the experimental group had their water bottles replaced with bottles containing Carlo Rossi chablis wine while the control group continued to receive only water to drink.

At 120 days of age, after the experimental animals had had only wine to drink for 60 days, each female was mated to the same stud male from the colony. Each of the females was mated four times over a period of 16 months. 


\section{RESULTS}

\section{Fecundity}

All females were mated four times to the same male. This involved placing the female into the male's cage for a 12-day period. The first three matings were successfull for all animals, but the fourth mating resulted in one pregnancy in each group. The remaining two animals in each group were then placed with the male again for a 14-day period but still did not conceive. At this time, the females were approximately 20 months old and the experimental group had been on wine for 18 months.

\section{Natality}

The control group produced a total of 84 pups, of which 1 was found dead on the day of birth and 4 died within 3 days of birth, for a $94.0 \%$ survival rate. The experimental group had a total of 94 pups; 3 were found dead on the day of birth and 1 died within 3 days of birth, for a $95.7 \%$ survival rate.

Table 1 gives the number of pups in each litter, and it can be seen from this table that there are not any differences between the two groups for the first two litters. However, the size of the third litter was drastically reduced in the control group, while two of the three animals in the experimental group maintained their high level of reproduction. Only one animal in each group conceived a fourth time. The control female had seven pups of which four survived; the wine female had one pup which was born dead.

\section{Growth}

All pups were weaned at 25 days of age and weighed then and again at 50 days of age. Pups in the second and third litters were also weighed on the day of birth. The birth weights for the second and third litters are given in Table 2; the control animals weighed more than the experimentals in both litters. A 2 by 2 ANOVA on these data gives a significant difference between the experimental and control groups $(F=36.78, p \leqslant .01)$ while the Litter and the Litter by Groups interaction are not significant.

At 25 days of age, the controls still weighed more than the experimentals, and a similar 2 by 3 ANOVA on these data gave a significant Groups effect
Table 1

Number of Pups per Litter

\begin{tabular}{crrrrr}
\hline \multicolumn{5}{c}{ Litter Number } \\
\cline { 2 - 5 } Female & 1 & \multicolumn{5}{c}{2} & 3 & 4 \\
\hline \multicolumn{5}{c}{ Controls } \\
1 & 11 & 11 & 4 & 7 & \\
2 & 11 & 13 & 4 & 0 & \\
3 & 12 & 7 & 4 & 0 & \\
Totals & 34 & 31 & 12 & 7 & 84 \\
& & Experimentals & & \\
4 & 12 & 12 & 15 & 1 & \\
5 & 9 & 11 & 10 & 0 & \\
6 & 13 & 10 & 1 & 0 & \\
Totals & 34 & 33 & 26 & 1 & 94 \\
\hline
\end{tabular}

$(F=66.54, p \leqslant .01)$ and a significant Groups by Litter interaction $(F=5.73, p \leqslant .05)$. An analysis of the simple effects of Litters for the control group gave a significant value $(F=6.24, p \leqslant .05)$, while the simple effect of Litters for the experimental group was not significant.

The control animals were still heavier than the experimental at 50 days of age and a 2 by 3 ANOVA of these data yielded a significant Groups effect $(F=16.17, p \leqslant .05)$, a significant Litters effect $(F=68.11, p \leqslant .01)$, and a nonsignificant Litter by Groups interaction.

\section{DISCUSSION}

Of the six females, only two, one in each group, conceived a fourth time. The other four animals failed to conceive even though they were placed with the male two different times for a total of 26 days. Since the same male was mated to all six females and two of the females did conceive, this failure must be due to the females. Thus it would appear that alcohol has little effect upon fecundity in the rat and that age is the limiting factor here.

With regard to natality, the two groups both had a total of 34 pups in the first litters. In the second litters, the controls produced 31 pups as compared to 34 for the experimental animals, so the groups do not differ through the second litter. However, in the third litters, the control females reduced their litter

Table 2

Mean Weight of Experimental and Control Animals at Birth, Weaning, and 50 Days of Age

\begin{tabular}{|c|c|c|c|c|c|c|c|c|c|}
\hline & \multicolumn{3}{|c|}{ Litter 1} & \multicolumn{3}{|c|}{ Litter 2} & \multicolumn{3}{|c|}{ Litter 3} \\
\hline & \multicolumn{3}{|c|}{ Days of Age } & \multicolumn{3}{|c|}{ Days of Age } & \multicolumn{3}{|c|}{ Days of Age } \\
\hline & 0 & 25 & 50 & 0 & 25 & 50 & 0 & 25 & 50 \\
\hline $\begin{array}{l}\text { Control } \\
\text { Experimental }\end{array}$ & & $\begin{array}{l}66.88 \\
45.71 \\
\end{array}$ & $\begin{array}{l}180.59 \\
149.82 \\
\end{array}$ & $\begin{array}{l}7.33 \\
7.25 \\
\end{array}$ & $\begin{array}{l}64.99 \\
56.21 \\
\end{array}$ & $\begin{array}{l}202.41 \\
177.96 \\
\end{array}$ & $\begin{array}{l}7.72 \\
6.83 \\
\end{array}$ & $\begin{array}{l}80.42 \\
48.86 \\
\end{array}$ & $\begin{array}{l}211.11 \\
182.63 \\
\end{array}$ \\
\hline
\end{tabular}


sizes to about one-third the size of their first two litters while two of the three experimental animals maintained their high output. While only one animal in each group conceived a fourth time, the control animal produced seven pups while the experimental animal had only one. Thus there is evidence that older female animals consuming alcohol continue to produce more pups in latter litters and then may experience a "burn out" where output drops drastically.

It has been reported by a number of researchers that prenatally administered alcohol reduces the birth weight of rat pups and the analysis of our birth weight data confirms this. Since the Litter effect and Groups by Litter interaction were not significant, it is concluded that this effect is not influenced by the age of the mother but rather is due solely to alcohol.

At 25 days of age, when the animals were weaned, we found that the experimental and control animals still differed but that in addition we had a significant Groups by Litters interaction. An analysis of simple effects indicated that this change was limited to the control group and that the third litters were heavier than the first two litters. Fuchs and Wagner (1963) have shown that alcohol suppresses oxytocin release and hence the milk supply, so the combination of this effect and the reduced litter size of the third control litters accounts for the significant interaction. Thus, at 25 days of age there is probably a direct effect and an indirect effect of alcohol upon weight. The direct effect occurs from the fact that alcohol reduced the milk supply of the experimental animals and thus kept their weight down; the indirect effect occurs because the control animals reduce their litter size as they become older and hence are better able to care for each individual pup.

When the pups reached 50 days of age, a difference was detected between Groups and between Litters. The Groups effect was expected as a carry-over from the differences that existed between Groups at birth and at weaning. The Litter effect was unexpected. Both groups displayed an increase in mean weight with each succeeding litter, the controls always more than the corresponding experimentals. This effect might have been expected in the third litters, since the control animals had smaller litters and larger pups at weaning, but we are unable to account for the increase from the first to the second litter at 50 days of age.

The six females were weighed at 120 days of age and at the end of the experiment. Fluid consumption was also measured over a $24-\mathrm{h}$ period at the end of the experiment, and the two groups did not differ significantly on any of these measures. The average alcohol consumption for the experimental group at the end of the experiment was $10.05 \mathrm{gm} / \mathrm{kg} / \mathrm{day}$.
While our sample sizes are small and the dosages of alcohol were not extreme, we conclude that alcohol apparently doesn't affect the fecundity of the rat but that it does affect the natality by maintaining reproductive output at a high level in latter litters, followed by a subsequent "burn out" effect. We confirmed that alcohol does reduce birth weight in the rat and that this is apparently not confounded with the age of the mother. Weights at weaning and at 50 days of age are also depressed by alcohol but the picture here is not as clear as at birth. We attributed these effects to alcohol and a combination of alcohol and age.

\section{REFERENCE NOTES}

1. Hanson, J. H., \& Smith, D. W. Fetal growth and morphogenesis and relationship to maternal alcohol intake. Paper presented at the meeting of the American Psychological Association, San Francisco, 1977.

2. Streissguth, A. P., \& Barr, H. Neonatal Brazelton assessment and relationship to maternal alcohol intake. Paper presented at the meeting of the American Psychological Association, San Francisco, 1977.

\section{REFERENCES}

Bianchine, J. W., \& TAYlor, B. D. Noonan syndrome and fetal alcohol syndrome. Lancet, 1974, 1, 933.

Butcher, R. E., Vorhees, C. V., \& Kimmel, C. A. Learning impairment from maternal salicylate treatment in rats. Nature New Biology, 1972, 236, 211-212.

Ferrier, P. E., Nicol, I., \& Ferrier, S. Fetal alcohol syndrome. Lancet, 1973, 2, 1496.

Fuchs, A. R., \& WAGNER, G. The effects of ethyl alcohol on the release of oxytocin in rabbits. Acta Endocrinology, 1963, 44, 593-605.

Golter, M., \& Michaelson, I. A. Growth, behavior, and brain catecholamines in lead-exposed neonatal rats: A reappraisal. Science, 1975, 187, 359-361.

Hall, B. D., \& Orenstein, W. A. Noonan's phenotype in an offspring of an alcoholic mother. Lancet, 1974, 1, 680-681.

Havlena, J., \& Werboff, J. Postnatal effects of control fluids administered to gravid rats. Psychological Review, 1963, 12, 127-131.

Jones, K. L., \& SMIth, D. W. Recognition of the fetal alcohol syndrome in early infancy. Lancet, 1973, 2, 999-1001.

Jones, K. L., Smith, D. W., Streissguth, A. P., \& Myrianthopoulos, N. C. Outcome in offspring of chronic alcoholic women. Lancet, 1974, 11, 1076-1078.

Jones, K. L., Smith, D. W., Ullelund, C. N., \& Streissguth, A. P. Pattern of malformation in offspring of chronic alcoholic mothers. Lancet, 1973, 1, 1267-1271.

Phillips, D. S., \& Stainbrook, G. L. Effects of early alcohol exposure upon adult learning ability and taste preferences. Physiological Psychology, 1976, 4, 473-475.

(Received for publication September 20, 1977; accepted October 14, 1977.) 